\title{
Community members' responses to the elective hysterectomy of an intellectually disabled girl
}

\section{Carol Hamilton}

University of Waikato

\begin{abstract}
The United Nations Convention on the Rights of People with Disabilities (2007) guarantees all intellectually disabled women the right to full bodily integrity. However, non-therapeutic sterilisations continue to be proposed as a means of managing the support needs of some members of this group. The opinions of community members, and whether men and women's views differ in relation to this topic, are rarely canvassed. Yet these views are significant as what constitutes acceptable social practice is ultimately set and contested at community level. This article reviews comments posted by male and female contributors to a BBC Have Your Say website about a mother's request for a hysterectomy for her 'severely disabled' daughter. Comments suggest the majority of posters endorse the request, however a marked difference by gender in reasons for support is evident. Gender differences are also noted in remarks about the social implications of requests of this kind and in the gender of contributors who thought this topic to be unsuitable for discussion in public forum. The difficulty some posters had with comments made from a rights-based advocacy position is briefly discussed as are possible limitations involved in using rights when debating the issue of non-therapeutic sterilisation.
\end{abstract}

Keywords: intellectual disability, sterilisation, gender, community, rights 
On Sunday $7^{\text {th }}$ October 2007 the BBC News Health website published an item about a request for an elective hysterectomy for a 15 year old "severely disabled" young woman (BBCa 2007). The item, "Mother seeks girl's hysterectomy", included statements from the mother, a medical specialist, the executive director of a large disability organisation (Scope), and a member of the Disability People's Council. Brief supporting items ran the next day. "Hysterectomy 'is an option' for girl" (BBCb, 2007), "Wait and see the best approach" (BBCe, 2007) and "Sympathy for an agonising decision” (BBCf, 2007). On Monday $8^{\text {th }}$ October 2007 a forum was initiated on the Have Your Say (HYS) website. Contributions were invited in relation to the following statement and questions:

"Is a mother right to ask for a hysterectomy for her disabled daughter? Speaking on a range of national television programmes, Alison Thorpe, 45, from Essex, says 15-year-old Katie, who has cerebral palsy, would be confused by periods and they would cause her indignity. Doctors are now seeking legal approval before carrying out the surgery. The disabled charity Scope said the operation would "set a 'disturbing' precedent for other disabled girls”. (BBCb, 2007)

- Should the mother have the right to make this decision without the permission of her daughter?

- Do you think she has made the right choice?

- Do you share Scope's concerns or have a personal experience to share?

The first comment appeared at $8.38 \mathrm{am}$, and the last at $16.43 \mathrm{pm}$ on the same day.

\section{Background}

Historically, sterilisation or medical procedures "which render(s) an otherwise healthy and presumed fertile person incapable of being a parent" (Law Reform Commission of Western Australia 1994, as cited in Spicer, 1999), were routinely carried out on large numbers of intellectually disabled people (Malacrida, 2006). Despite what is known of the medical and social impact of this procedure, non-therapeutic sterilisation is still considered a viable option (Gomez, 2010) as a form of sexuality and reproductive capacity management (Roets, Adams \& Van Hove, 2006) and as an aspect of the support requirements of individuals with severe impairments (Bersanti, 2008). Sterilisation is also far more likely to be mooted for intellectually disabled girls and women than for their male counterparts (Brady, 2001). Recent legislative and policy developments in a number of countries have sought to regulate nontherapeutic use of this procedure. In the USA, 39 states have statutes or case law related to when and under what circumstances non-therapeutic sterilisation is to be considered (Begun, 2008). Legal requirements vary widely, ranging from direct prohibition to approval for sterilisation in certain circumstances depending on the reason for the process and how the request is initiated. In the United Kingdom, formal requests for sterilisation of intellectually disabled adults, or minors, requires application to the court system. Whether the procedure is "in the best interests" of the 
individual concerned is then adjudicated with regard to prior case-law (Stansfield, Holland \& Claire, 2007). However, using case-law precedent rather than direct legislative prohibition leaves disabled men and women vulnerable to best interest adjudications made from the perspective of 'intellectual disability' as a global functional limitation (Dowse, 2004). In Australia, the principle of adjudication by prior case law also applies. In this regard, the Marion case, concerning application to the court for a non-therapeutic sterilisation of a teenage girl with intellectual disability, set a significant legal precedent. Re Marion secured adjudication of the right to reproduce as a legal matter rather than a decision to be made by parents, carers or medical practitioners. However, subsequent judicial decisions have not endorsed Marion and debate continues about who decides whether the person concerned is able to consent and at what age such judgement can be made (Dowse, 2004). In New Zealand, sterilisation of intellectually disabled people over 18 judged unable to consent is referred to the Family Court, where prior case law provides the basis for judgement. For those under 18 it is possible, albeit not recommended, for parents or guardians and medical professionals to endorse a decision to sterilise without recourse to the court system (Schrenk, personal communication, March 13, 2011). The countries noted above are part of the 90 member states that have ratified the United Nations Convention on the Rights of People with Disabilities (UNCRPD, 2007). Article 17: "Every person with disabilities has a right to respect for his or her physical or mental integrity on an equal basis with others", and Article 23: "states parties must take effective and appropriate measures to eliminate discrimination against persons with disabilities in all matters relating to marriage, family, parenthood and relationships, on an equal basis with others", are of particular relevance to the use of non-therapeutic sterilisation. These statements signal that the status of intellectually disabled people in these areas should be no different from that of non-disabled people.

It is hard to gauge how long it might take signatory nations to resolve existing discrepancies between the spirit and intention of these Articles and their legal processes and clinical practices. Despite some attitudinal shifts, many people still experience a deep sense of unease when sexuality and intellectual disability are mentioned together (Hingsberger, 1997). Intellectually disabled people themselves find it difficult to negotiate this aspect of their 'ordinary lives' (Kelly, Crowley \& Hamilton, 2009), with women experiencing greater overall difficulty in this area than their male counterparts. In part this difficulty can be attributed to the "policed, defensive silence" (De Palma \& Atkinson, 2007, p. 62) that pervades key aspects of this topic. Yet when open discussion is inhibited, feelings of shame, disgust and anxiety rather than policy processes shape the actions taken in respect of intellectually disabled people's sexuality (Hamilton, 2009). In the area of sexuality, sterilisation and intellectually disabled people, a lack of open discussion coupled with the legal minefield surrounding this issue creates conditions for the use of these procedures to continue.

\begin{abstract}
Aim
This article reviews comments made in response to the three forum questions on the HYS site. It was initiated to promote discussion about a topic that, despite the known health and social effects of this procedure, rarely appears in the intellectual disability research literature. It was also compiled to connect the lives a specific group of vulnerable people more directly to contemporary community debates that have seen the struggle for access to rights at a personal level become part of a worldwide political agenda (Plummer, 2001). In addition, this review afforded the chance to
\end{abstract}


provide information about the thoughts of a group of community members who are not directly involved with an intellectually disabled person. As greater numbers of more severely intellectually impaired young people leave home to live in community settings, it may be useful for researchers and disability service providers to have a more in-depth knowledge about the range of opinions held by individuals not directly connected to members of this group in the area of sexuality and intellectual disability. Further, this review provides a significant opportunity to capture the opinions of a 'community members' cohort who differ from the more usual under and postgraduate student group who frequently appear as a 'general community opinion' norm in intellectual disability and sexuality survey samples (Karellou, 2004). It also preserves a record of the opinions of a number of male respondents who rarely feature in this dataset (Wilson, Parmenter, Stancliffe, Shuttleworth \& Parker, 2010). In this regard, early findings about web discussion site use by social groups that comments posted in this location are likely to capture the opinions of white, first world, well off and well educated males (Coomber, 1997) were useful in developing this aspect of the review focus.

Key ideas from two contemporary studies of opinions of community members about intellectual disability and sexuality were used to isolate the characteristics of the community member cohort used for the purpose of this review: Cuskelly and Bryde's (2004) gendered canvass of the opinions of a small group of community members (in this case including 33 psychology students), about the sexual expression of intellectually disabled people; and Esterle, Sastre \& Mullet's (2008) socio-sexual questionnaire given to a random group of "laypeople ... walking along city sidewalks” (Esterle, Sastre \& Mullet, 2008, p. 219) in Lyon, France. Following Esterle et al. (2008), comments posted are reviewed as the opinions of a 'random' selection of unique individuals whose social and occupational backgrounds are unknown. Thus, comments posted by respondents in the UK are used because the request is local to members of this 'community' who, in addition, are all bound by the same set of legal requirements about sterilisation procedures. In reference to Cuskelly et al. (2004), only opinions offered by UK posters whose comments contained no stated family/personal connection to an intellectually disabled person or support system are included. Lastly, in accordance with HYS website regulations, comments used were posted by signed-up members of the site. Site management of HYS also includes moderation of comments and maintenance of an FAQ section.

\section{Method}

A total of five hundred and thirty six comments was posted in response to the trigger questions. All were initially sorted into community member categories using information contained in the posts. Forty comments posted by individuals from outside of the UK, identified by sign-off location, were put to one side at this time. Five categories of UK post comments emerged - General Community Member (GCM), Family Member, Carer of Disabled Person, Disabled Person and Friend/Acquaintance. The GCM category comprised the largest group. GCM responders by gender were initially ascertained through sign-off signature - for example Peter Berry, Sue Scott, or Mrs Trellis. Signatures not conforming to conventional male/female names were designated gender uncertain (GU) then reassessed for information within the comments that might more clearly indicate gender affiliation. The aggregate of GU posts that could not be identified were also put to one side. A total of 369 GCM posts consisting of comments by 185 men and 184 women forms the basis for this review. 
Table 1. Total HYS Comments by Category and Gender

\begin{tabular}{|lrrrr|}
\hline HYS Post Categories & Men & Women & G.U. & Total \\
\hline All Posts (excluding GU's) & & & & 536 \\
General Community Members (GCM's) & 185 & 184 & 97 & 466 \\
Family Member & 9 & 8 & - & 17 \\
Carer of disabled person & 1 & 5 & 1 & 7 \\
Disabled person & 2 & 2 & - & 4 \\
Friend/Acquaintance & 1 & 1 & - & 2 \\
Outside UK & & & & 40 \\
\hline
\end{tabular}

All GCM posts were read three times, then coded into sub-category theme areas. The majority of comments posted by both men and women related to trigger question one - the call for responses to the idea of the mother's right to request a hysterectomy for her daughter. Three sub-groupings of opinions emerged from this aspect of the coding process: agreement with request; Mother and Doctor joint decision; and disagree with request. These comments plus additional remarks made about disability service agencies are reviewed in the second half of the article.

Table 2. Mother's Right Responses by Subcategory and Gender

\begin{tabular}{|lcc|}
\hline GCM Posts & Men & Women \\
Total Comments & 94 & 109 \\
Agreement with Request & $52(55 \%)$ & $82(75 \%)$ \\
Mother and Dr Joint Decision & $19(20 \%)$ & $7(6 \%)$ \\
Disagree with Request & $23(25 \%)$ & $20(18 \%)$ \\
\hline
\end{tabular}

Forty comments offering alternative choice suggestions were coded in response to trigger question two - do you think she has made the right choice?

Table 3: Number of Alternative Suggestion Posts by Gender

\begin{tabular}{|lll|}
\hline GCM Gender Category & Men & Women \\
\hline Alternative Choice Suggestions & $8(.4 \%)$ & $32(17 \%)$ \\
\hline
\end{tabular}


Finally, thirty-seven comments directly related to the personal story aspect of trigger question three - do you share Scope's concerns or have a personal story to tell? were isolated. Direct quotes from these comments are included in the second half of this article.

As is usual on HYS news sites, the substance of comments posted was brief due to the limit placed on the number of letters allowed. The length of posts ranged from single words to a maximum of eight lines of discussion. Examples of the reasons used by GCM men and women to substantiate the opinions they posted are outlined below.

\section{What Posters Said}

The majority of posters agreed with the mother's request, with many sensitively acknowledging the difficulties this issue raised. Considerable degrees of sympathy for the position of both mother and daughter were expressed in comments made by men who expressed agreement with the mother's request:

This is a massive heart-wrenching decision (Rich)

I thank God that my wife and I did not have to face tough choices for our kids (Brian)

The idea that the daughter's quality of her life may already have been compromised due to the severity of her impairment effects, plus comments about her vulnerability to abuse were also offered:

I agree if the onset of puberty is going to add even more pain to an already pain-filled life (Ian)

It is important to consider the risk of rape and what would happen if the girl became pregnant (Jonathon)

Of note were the twenty-six additional statements made about the opinions of others by posters agreeing with the Mother's right. These comments contained examples of 'reasoned points of view' up to far more forcefully held opinions about the legitimacy of disability organisation's views in particular:

Unlike Scope, I think that this does not set a precedent (Paul)

Scope is wrong!!! It's not their problem; it's her mothers (Dmitir)

Scope's views are irrelevant and predictably the moral nonsense from religions zealots and technophobic luddites is, as ever, devoid of scientific and legal understanding (George)

The legitimacy of the opinions of non-disability service agency personnel also came in for sharp criticism:

I would side with the mother 100\%. Once you start getting politics involved, laws, religion and any other of the idiotic do-gooder types which seem to poke their noses in, this is when it becomes dangerous to everybody (Guy) 
It's a matter for the parent or guardian to decide - NOT social workers, social engineers or those who merely think it wrong because of their own limited views (Jack)

Try looking after a badly handicapped, doubly incontinent girl having a period. Do this for say 6 months and then come back with your glib theoretical arguments that might be fine for an edition of 'The Moral Maze' but have no place in the real world (Andrew)

Criticism of rights-based points of discussion used to prevent the procedure were also aired:

The "Rights" brigade seems to forget that rights carry obligations. If this child is not given the hysterectomy will she have any hope of being able to fulfil her obligations to the child? (Barry)

I am fed up with the "Human Rights" brigade. Many people with CP can live relatively 'normal' lives but Katie [daughter] can't. Does she not have a "right" to circumstances as considered by her mother? (Jim)

Male posters who disagreed with the idea of the mother as decision maker included those who proposed the idea of a joint decision:

This incredibly difficult decision lies exclusively with the Mother and the Doctors involved (George)

However, some posters did not think this provided a solution to the problem:

I feel this is an exceptionally dangerous precedent. The notion of 'quality of life' needs some serious examination or where does it end? This decision affects the legal framework... it would be very wrong indeed for it to be decided by just parents and doctors (Tom)

I don't like the idea... the doctors involved should 'do no harm' and not go sterilising a girl for the sake of the mother's wish (Stephen)

It was also mooted that this decision be made by a third party, possibly to include medical professionals:

A panel of experts are the only people qualified to make such a decision (Mark)

Others who disagreed with the mother's request queried her motive. Strong emotions also featured in these remarks:

The idea of carrying out a serious surgical procedure which has a supposed benefit to the carer causes me concern (Jeremy)

Save who from the "pain and indignity" menstruation causes? (Jon)

The mother is selfish. She wants to do it because SHE wants to (Vladimir)

However, the impact of a decision to sterilise on the social environment was also raised:

It sets such a dangerous precedent that the answer is no. Opening the door on eugenics could let some monsters through (Joe) 
Sympathy for the mother also featured in comments posted by women in support of the request. Strong emotions also featured:

The old adage 'mother knows best' applies in this heartbreaking case (Chris)

CARING MOTHERS KNOW THEIR CHILDREN BETTER THAN ANYONE IN THE WORLD (Suzanne)

Some posters endorsing the mother's position expressed anger towards those who queried the mother's right to make the request:

You Human Rights Left Wing People really do go on my nerves, who are you to say what's best for the daughter? (Claire)

They should support her instead of jumping on the pc do gooders wagon who know nothing!!!!! of her circumstances (Julie)

Suggestions that others, including service agency personnel, might have something valid to contribute to this debate were strongly refuted. Some women found the use of rights based approaches to discuss the issue of care and support very difficult:

Would all the people against her having a hysterectomy be there to care and look after this girl? (Claire)

I'd like to ask Scope how much help and support they have provided to the Thorpe family over the past 15 years (Megan)

Unsurprisingly, sterilisation as a relief from menstruation for both mother and daughter was raised:

A menstrual cycle is a messy job (Angelwingz white)

She is doubly incontinent, something which must cause [the daughter] distress and discomfort (Lynne)

Imagine that every time you have a period your Mother has to insert and remove your tampons for you (Claire)

Sterilisation as protection from the unwanted outcome of any sexual encounter was also mentioned:

It must always weigh on the mind of parents of mentally handicapped children that future carers will not protect them from ill-advised sex and pregnancy (April)

There are some unscrupulous men who would still take advantage of this poor girl (Doreen)

Fewer women than men suggested that the opinion of doctors and medical specialists should be sought:

It's really up to the mother and the doctors (Lady K)

In contrast, twenty posts by women included expressed doubt up to complete disagreement with the mother's motive for this request:

Is this is a case of indignity to the daughter or inconvenience to the mother (Marie)

The mother has no right to play God like that (Molly) 
I wouldn't dream of intervening in my daughter's development just to save her indignity or discomfort (Merryl)

The wider social implications of sterilisation were briefly touched on:

In a wider context this sets a dangerous precedent, which smacks of eugenics (Cheryl)

The idea of the daughter herself making this decision was also mooted:

Has anyone asked the girl herself how she feels about having this operation? (Kirsten)

It's her rights under the HUMAN RIGHTS ACT 1998 (dreamcatcher)

Notably, female responders only posted statements about the daughter's right to have a say about this decision.

Eight male and thirty-two female posters offered a total of 40 comments in relation to trigger question two. Comments by men directly focused on use of alternative biomedical procedures and the question of clinical effects. A range of suggestions were mentioned, including:

A hysterectomy should not be taken lightly. There are secondary effects (Carlos)

How about chemically induced infertility or taking a contraceptive? (Alex)

Why don't they give her depo-provera? (Tom)

Why not collect eggs from her and put them in cryo-storage? (James)

Posts by women in this area were considerably more detailed. Comments included possible use of alternative contraceptive methods, with nineteen posters mentioning a variety of less invasive possibilities:

Why not just give her the pill? (Jane)

The Depovera injection is well known to stop periods in a lot of women (Gemma)

There are injections and implants she could have (Claire)

... or fitting a coil? (Alison)

Potential health effects of the solutions offered above were commented on by eight, including the ethical minefield inherent in initiating surgical or chemical procedures:

Warnings, depression, migraine, visual disturbances, thrombo-embolic or cardiovascular disease, do not readminister if patient develops pulmonary embolism, small increased risk of rest cancer. SAFE? (Jane)

Overall, few comments were posted in response to this question with only $17 \%$ of GCM women and .4\% of GCM men offering suggestions. The significant discrepancy in comments by gender clearly indicates the different background experiences of menstrual management drawn on by posters to substantiate their comments.

No direct personal experiences were posted by male GCM's in response to the third trigger question as the review method used eliminated posts from men who acknowledged personal or family connections to an intellectually disabled person in 
their comments. However, twenty posts about aspects of the ethical dilemma created by the mismatch between this request and the social system in which it is located were offered.

There seems to be two topics here, the comfort and dignity of the individual girl and the idea that it's 'sterilisation of undesirable people' (Benny)

Should severely mentally handicapped people be allowed to have children? That is a really uncomfortable question (Benny)

In our horribly over-regulated society, where do we draw the line? And 'who draws it' (Ralph)

Consideration of past moves to eliminate by sterilisation ethnic and bodily characteristics considered socially and economically undesirable featured:

As long ago as the 1930's the Nazis started their rule of terror with measures such as these (Ralph)

Sterilisation of the "racially unfit" conducted by Hitler's National Socialists (Tom)

Right up to the 1970's, maybe beyond that, it was not unusual to forcibly abort women with learning disabilities as well as sterilising them (Jeremy)

Yet this request did not necessarily represent the start of a significant general moral decline for some posters:

This isn't the "slippery slope". Most decisions worth taking require careful and considered judgement rather than blind and blanket restrictions (Colin)

Surgery on the vulnerable in itself can be an abuse (Simon)

A very bleak view of the workings of 'naturalised' universe substantiated the opinions of eight posters, for example:

This child should be kept as nature designed her (Colin)

It's interference with nature, which would surely have let this poor girl die (Nik)

I believe in the human animal and sometimes a decision has to be made to alleviate any form of distress and suffering. Make the right decision for the human animal (Andy)

However a poster responding to these very bleak 'natural' state opinions produced the following point:

I didn't need a hysterectomy when I was a child and neither do any other children who didn't have disability. So this child shouldn't be any different (Jack)

Four posts outline the potential for legal recourse to help adjudicate in this decisionmaking process.

If she is mentally capable then the decision is hers in law (Douglas)

Such decisions should be referred to the courts (Ellis)

Significantly only two posters commented favourably on the positive contribution made by disability support systems to the lives of intellectually disabled people. 
This would not be as much of an issue if only the Govt would reassess their priorities and provide a lot more assistance to disabled people and their carers (Richard)

This country should be proud of its army of carers, who take both the workload and awkward decisions away from us weaker individuals (Mal)

As a number of these examples reveal, many of the issues raised by men in this section were thoughtful and considered.

Definition of the GCM category also limited the number of personal stories offered by women. Posts in this section also showed that some had thought deeply about this request.

While I have the upmost sympathy where does this stop? (Kate)

Compulsory sterilisation of the disabled has always been done in the name of 'common sense', overwhelming practical necessity, and even 'humanity'. No surprise that it should return to us now (Stella)

I feel that this is one of those debates like euthanasia - it is easy to hold the moral high ground until it affects you (Sarah)

A number of the posts related to personal menstrual difficulties and difficulties experienced by other women:

I'm a 41 year-old woman facing a hysterectomy after 20 years of hell (Glossop Goddess)

I just hope the daughter is not one of the thousands of women (me included) who are in agony for a couple of days a month with chronic period pain (Sheila)

I remember plenty of able-bodied girls at school and at work who suffered horribly (Nightowl)

However, not all viewed menstruation as a necessarily painful experience:

I'm 15 too and my periods don't cause me huge pain, upset or inconvenience. We're not living in the 1950's anymore (Sarah)

Surrounding environmental and cultural difficulties involved in managing aspects of the menstrual cycle for some were a source of great frustration.

This poor girl can't just nip to the toilet to "change", her mother etc are going to have to do it for her. I can't imagine being able to do this in the toilets in Tesco's (Mizzdaizyduke)

I question the 'indignity' of menstruation. The only indignity is that it is still seen as a taboo to be covered up. This has more to do with the convenience of society to ignore issues faced by disabled people and women in general. Will we castrate boys next? (JC)

\section{Discussion}

Well known points of debate about use of sterilisation-related procedures as an option for intellectually disabled women - quality of life, personal incapacity, menstrual and reproductive management, sexual vulnerability and rights - all featured in the comments posted by GCMs. Endorsements of medicalised approaches posted by 
GCMs of both genders were framed within notions of disability as a personal and family tragedy. Eugenics-related fears about disabled women's reproduction could also be found in the 'in the best interests of all concerned' subtext through which endorsements of the mother's right were offered. GCMs posts considering the wider social difficulties inherent in medicalised approaches drew strongly worded, emotive responses from other GCMs. These interchanges suggest that managing debates about how to fully implement the spirit and intention of Articles 17 and 23 of the UNCORPD will need a coordinated, interagency approach.

Well-articulated differences in social position between genders also emerged in the comments posted. More women than men are involved in key aspects of direct bodily care, thus it is no surprise that the care of vulnerable people and their direct support networks as a rights issue of equal consideration should be an important issue for many women (in the disability sector see, McGraw \& Walker, 2007). While more men than women provide clinical expertise in relation to vulnerability, care and support, it is unsurprising that supporting women as carers and involving medical personnel in decision-making could be important issues for many men. However, only marginally more men than women disagreed entirely with the idea of the mother having a right to decide on behalf of her daughter, suggesting that some of these more traditional notions of gender roles in caring have successfully been challenged.

Including gender as an aspect of this review brought to light two less well-defined areas of consideration. The first relates to the significant number of not a suitable topic comments posted almost exclusively by GCM men. During the initial analysis a group of posts - 42 by men and 3 by women - made solely in relation to a not $a$ suitable topic for discussion set of responses were isolated. Of these, thirty-two men agreed with this comment. Remarks ranged from polite queries about the questionable value of the public nature of this discussion to heated indignation expressed towards BBC personnel for presuming that this subject could possibly be considered a fit topic for debate.

Does anyone else share my thought that this is not a remotely suitable topic for public discussion? (Steve)

I can't believe how low the BBC have stooped for the sake of sensationalism (Paul)

I find this question really abhorrent BBC should be ashamed of itself (Tom)

Ten male posters disagreed with these remarks. In a direct response to the 'not a remotely suitable topic' comment above, one poster suggested:

Since you ask, no I don't agree with you. HYS is for people to express their opinion, so it is therefore a suitable discussion topic (Harry)

Others suggested that these comments simply closed off discussion of a legitimate subject of public scrutiny. These posts linked the issue to wider social concerns and broader political frameworks in substantiation of their disagreement:

Refusal to discuss thorny issues is simply a step along the road to ignorance... should we not discuss euthanasia, abortion, sex and paedophilia because some people find it distasteful? (Tom)

As a society it is beholden upon us to come to informed decisions on the rights of individuals vs the rights of parents/carers vs the rights of the government to medically intervene in such cases (Rob) 
For one, that such public debates should take place was a deeply personal issue:

I don't want to live in a society where we cannot discuss such matters and ask these questions. It is extremely important to that the wider society can come together in order to define its shared values and prevailing attitudes (Thomas)

In contrast, only three posts by women considered this topic unsuitable:

I find it morally wrong that we should debate this private and highly sensitive matter. (Laura)

This has become a society where reporters literally crawl under and in beds to give their sordid stories (Anne)

Please REMOVE this topic from HYS. It does not benefit the BBC to promote discussion in such a personal matter (Mairaid)

Six offered affirmative comments as discussion end-points and the following are included as examples:

Surgery on a person incapable of decision-making should be subject to a great deal of public scrutiny (Jane)

Not one of us can be sure that this worrying question won't arise in one of our families (Patricia)

This sub-group of comments suggests that a cohort of people, including men with a degree of social standing may find debate about this issue extremely difficult.

Secondly, the degree of difficulty some GCM men and women had with the rights-framed views of service organisation personnel was also an unexpected outcome of the review process. This difficulty suggests that blanket use of the concept of rights as an advocacy tool designed to instigate changes in attitude towards nontherapeutic sterilisation might need careful consideration. Rights based approaches to persuading others to share a particular viewpoint about a controversial matter can create a divisive "I'm ok/you're not ok" binary, from which it is difficult to move forward (Edgett, 2002). Rights issues can also been seen as manipulative, through well-known links between the concept of rights and the political ends to which it can be deployed (Heinz, 2008). In this scenario, rights calls become trump cards used to manipulate conversation by censuring one kind of conduct while tacitly urging another, rather than encouraging beneficial two-way conversations through which critical examinations of the social conventions surrounding the issue can be sustained.

\section{Conclusion}

A number of methodological drawbacks are involved in undertaking sample reviews of comments taken from public sources. In the case of this review, a broader range of questions would have elicited responses of greater depth and complexity. Being able to include information about the age, marital status, ethnicity and sexual orientation of GCM posters would also have allowed these important variables to add further dimensions to the discussion. Secondly, posts used represented the views of United Kingdom GCM's only -primarily posted from northern and southern England. A detailed comparison of GCM views from the different countries that make up the UK may have added yet further insight. However, this review was undertaken to further 
discussion about how to ensure that all intellectually disabled girls and women are guaranteed the right to bodily integrity promised by the UNCROPD. As such, it is important that key individuals who may experience discomfort with the subject matter do not compromise debates about this issue. It is also important that debates are held in conjunction with other discussions now taking place in relation to what a more holistic 'good life' for intellectually disabled people might look like (see, for example, Johnson \& Walmsley, 2010). I also suggest that greater consideration be given to what role might be played by the wider community member cohort isolated in this review in the development of this vision. Would attempting to canvass the opinions of a representative group of not a suitable topic responders about what an holistic 'good life' for all intellectually disabled people might look like, help make that life more attainable?

This YHS topic was removed from the BBC site four days later. Was the decision to remove it so quickly influenced by the 'not a suitable topic' comments? Perhaps not directly, but when silence remains an acceptable means by which complex social issues are managed, coming together as a community to enact in practice what our shared values are about this issue becomes that much more difficult.

\section{References}

BBCa (2007, October 13). Have Your Say. Retrieved from http://newsforum.bbc.co.uk/no1/ thread.jspa?sortBy=2and

BBCb (2007, October 13). Hysterectomy 'is option' for girl. Retrieved from http://news.bbc.co.uk/2/hi_news/england/merseyside/7034623.stm

BBCc (2007, October 13). Mother seeks girl's hysterectomy. Retrieved from http://news.bbc.co.uk/2/hi/health/7032736.stm

BBCd (2010, January 27). The Frozen Girl Debate. Retrieved from http://news.bbc.co.uk/2/hi/6230045.stm

BBCe (2007, October 13). Wait and see the best approach. Retrieved from http://news.bbc.co.uk/2/hi/health/7033680.stm

BBCf (2007, October 13). Sympathy for an agonising decision. Retrieved from http://news.bbc.co.uk/2/hi/uk_news/7033609.stm

Begun, H. (2008). Empirical Analysis of Sterilisation of Mentally Handicapped Individuals in the United States. Journal of Nursing Research, 1(2), 13-19. Retrieved from http://repository.upenn.edu.josnr

Bersanti, H. Jr. (2008). If "Growth Attenuation" is the Answer ... What is the Question? Retrieved from www.wou.edu/ bersanh

Brady, S. H., (2001). Sterilisation of Girls and Women with Intellectual Disabilities: Past and Present Justifications. Violence Against Women, 7(4), 432-461.

Coomber R. (1997). Using the Internet for Survey Research. Sociological Research Online, 2(2). Retrieved from http://www.socresonline.org.uk/2/2/2.html

Cuskelly, M. \& Bryde, R. (2004). Attitudes towards the sexuality of adults with an intellectual disability: Parents, support staff and a community sample. Journal of Intellectual and Developmental Disability, 29(3), 225-264.

DePalma, R. \& Atkinson, E. (2007). Strategic Embodiment in Virtual Spaces: Exploring an on-line discussion about sexualities equality in schools. Discourse: Studies in the Cultural Politics of Education, 28(4), 499-514. 
Dowse, L. (2004). Moving Forward or Losing Ground? The Sterilisation of Women and Girls with Disabilities in Australia. Disabled Peoples' International (DPI) World Summit, Winnipeg, September 8-10. Retrieved from http://www.wwda. org.au/steril3.htm

Edgett, R. (2002). Towards an Ethical Framework for Advocacy in Public Relations. Journal of Public Relations Research, 14(1), 1-26.

Esterle, M., Sastre, M. \& Mullet, E. (2008). Judging the Acceptability of Sexual Intercourse Among People with Learning Disabilities: French Laypeople's Views. Sexuality and Disability, 26, 219-227.

Gomez, M.T. (2010). Response. Bioethical Inquiry, 7, 375-376.

Hamilton, C. (2009). Now I'd Like to Sleep With Rachael - researching sexuality support in an agency service group home. Disability and Society, 24(3), 303315.

Heinz, E. (2008). Even-handedness and the Politics of Human Rights. Harvard Human Rights Journal, 21(1), 8-46.

Hingsberger, D. (1997). Dave Hingsberger’s 'Hot Fudge Sunday'. TASH Newsletter, 23(5), 10-11.

Johnson, K. \& Walmsley, J. (2010). People with Intellectual Disability: Towards a good life? London, UK: The Policy Press.

Karellou, J. (2003). Development of the Greek Sexuality Attitudes Questionnaire Learning Disabilities (GSAQ-LA). Sexuality and Disability, 21(2), 133-135.

Kelly, G., Crowley, H., \& Hamilton, C. (2009). Rights, Sexuality and Relationships in Ireland: 'It'd be nice to be kind of trusted'. British Journal of Learning Disabilities, 37, 308-315.

Lapinsky, M. \& Rimal, R. (2005). An Explication of Social Norms: Understanding Specific Events Within That System. Communication Theory, 15(2), 127-147.

McGraw, L.A. \& Walker, A. J. (2007). Meanings of Sisterhood and Developmental Disability: Narratives from White Non-Disabled Sisters. Journal of Family Issues, 28, 474-500.

Malacrida, C. (2006). Contested memories: Efforts of the powerful to silence former inmates' histories of life in an institution for mental defectives. Disability and Society, 21(5), 397-410.

Plummer, K. (2001). The Square of Intimate Citizenship: Some Preliminary Proposals. Citizenship Studies, 5(3). 237-253.

Roets, G., Adams, M., \& Van Hove, G. (2006). Challenging the monologue about silent sterilisation: Implications for self-advocacy. British Journal of Learning Disability, 34, 167-174.

Spicer, C. (1999). Sterilization of Women and Girls with Disabilities: A Literature Review. Retrieved from http://www.wda.org.au/steril.htm

Stansfield, A., Holland, A. \& Claire, I. (2007). The sterilisation of people with intellectual disabilities in England and Wales during the period 1988 to 1999. Journal of Intellectual Disability Research, 15(8), 569-579.

United Nations Convention on the Rights of People with Disabilities, (2007). Retrieved from http://www.un.org/disabilities/convention/ conventionfull. shtml

Wilson, N.J., Parmenter, T.R., Stancliffe, R.J., Shuttleworth, R.P. \& Parker, D. (2010). A masculine perspective of gendered topics in the research literature on males and females with intellectual disability. Journal of Intellectual and Developmental Disability, 35(1), 1-8. 


\section{Biographical Note}

Carol Hamilton is a Senior Lecturer in Disability and Inclusion at the University of Waikato. She completed her $\mathrm{PhD}$ as a mature student, researching in the area of intellectual disability and sexuality support in an agency service group home. Her current research interests are in clinicians' attitudes to sterilisation and young intellectually disabled girls and women and wider community attitudes and beliefs in the area of disability, ability and social inclusion. 